\title{
Effects of Aloe Vera in Local Massage Oils in Alternative Medicine for the Treatment of Joint Pains: A Double Blind Study
}

\author{
Innayat Ullah Arain, Amina Husnain, Aisha Talat
}

\begin{abstract}
Introduction: Aloe vera has been reported to have effects upon skin, joint pains and diabetes but without scientific evidence. It has never been studied in isolation as a single drug. Our study was a small study to study the symptom lowering effects of Aloe Vera gel when used in combination with a topical massage oil.
\end{abstract}

Patients and Methods: A prospective double blind interventional study was conducted with patients of osteoarthritis knee randomized in two groups of patients (20 in each). Both groups were given topical oil for massage over the affected joints. They were provided oral analgesic tablets in fixed numbers and during follow up Visual analogue score and number of tablets used was taken as measure of alleviation of symptoms.

Results: Both groups comprised of 20 subjects each and had similar characteristics for age/sex/laterality of joint involved. The epidemiological characteristics of

Conflict of Interest: No

Funding Source: No

Arain I.U. ${ }^{1}$

Associate Professor of Anesthesia

Avicenna Medical College, Lahore

Husnain A. ${ }^{2}$

Associate Professor of Medicine

SIMS/ Services Hospital, Lahore

Talat A. ${ }^{3}$

Associate Professor of Pharmacology

$\mathrm{CMH}$, Medical College, Lahore the groups were similar. Group - A used Topical Massage Oil without addition of Aloe Vera Gel while Group B used the same oil with addition of the gel. It was observed that patients who had been given massage oil with addition of Aloe Vera gel showed less use of oral analgesics during study period and their VAS scores were less as compared to the Group - A who were using the same massage oil but without Aloe Vera Gel. Conclusion: Aloe Vera as local application seems to improve pain relief and decrease oral analgesic use in patients of osteoarthritis knees who are being treated with local massage oils of alternative medical origin. Further studies need to be done to reach a conclusion. Key Words: Massage Oil, Aloe Vera, Analgesia.

\section{Introduction}

Aloe vera has been used for centuries due to the beneficial effect it has on the skin. Aloe vera is said to encourage skin rejuvenation, healing of wounds and treatment of sunburn. It is also used to help in relieving arthritic pain, improving blood circulation, reduce scarring and shows anti-inflammatory properties. Some ancient sources have advocated its oral and local use in joint disorders.

Extracts from Aloe vera are widely used in the cosmetics and alternative medicine. Frequently it is proposed to have rejuvenating, healing, or soothing properties. ${ }^{1}$ Scientific evidence of the effectiveness or safety of Aloe vera extracts for these uses are lacking and what positive evidence is available is frequently contradicted by other studies. ${ }^{2-4}$ Aloe vera massage oil is claimed to have healing qualities which makes it a good choice to use on its own, or to include when mixing a massage oil or preparing a carrier oil blend for traditional massage. Aloe vera leaves contain phyto- 
chemicals such as acetylated mannans, polymannans, anthraquinone C-glycosides, anthrones, other anthraxquinones, such as emodin, and various lectins. ${ }^{4-6}$ There is some preliminary evidence to suggest that oral administration of aloe vera might be effective in reducing blood glucose in diabetic patients and in lowering blood lipid levels in hyperlipidaemia. ${ }^{7,8}$ The topical application of aloe vera ia said to sooth aching joints but does not seem to prevent radiation-induced skin damage. ${ }^{4,7}$ Feily and Namazi argue that evidence regarding wound healing is contradictory. ${ }^{3,4,6,7}$ Same review has found that Aloe has not been proven to offer protection to humans from sunburn. A 2007 review of aloe vera use in burns concluded, "cumulative evidence tends to support that aloe vera might be an effective intervention for use in burn wound healing for first- to second-degree burns. Very little scientific work of similar nature is available for joint disorders. A 2014 Cochrane review found no strong evidence for the value of topical application of aloe vera to treat or prevent phlebitis caused by intravenous infusion. ${ }^{8,9}$ Many traditional massage oils have been used since long time to alleviate joint pains and many contain Aloe Vera. No known effect of aloe vera has been known in recent times upon joint pains it may-be possible that because of its effects on the skin Aloe vera maybe facilitating, augmenting or potentiating the effects of other aromatic oils in the traditional medicine. A small scale interventional study was designed to see the effect of addition of Aloe Vera to such preparation for use in joint pains. The purpose was that the effect if any should be documented.

\section{Materials and Methods}

A popular off the shelf commercially available massage oil was obtained. Aloe vera gel was added to half of the packs [Composition of the Branded Oil: Staff Tree seed Oil(Malkangni), Pheno Greek Oil(Maithee ), Nigel Satiwa Oil (Kalwangee), Turpentine Oil, Colchicl - Cormus Oil (Soranjan Talkh) and Fish Oil]. Weight / weight. Labels were removed from all the packs and all were labeled numerically as 1, 2, 3, 4 blinding the user and the prescriber to the original formulation of the product. All the subjects were counseled and were told about the intent of the study culminating the process in a written formal consent. Forty patients were inducted through Orthopedic and medical Outpatients who came with bilateral knee pain of more than 6 months standing, where the age was abo- ve 45 years and there was no history of trauma to the limb involved. Gender bias was avoided strictly. In order to control confounding variables only cases with osteoarthritis knees were included. The amount of pain was measured before treatment using a VAS (visual analogue score). Every patient was given 20 tablets of diclofenac sodium $50 \mathrm{mg}$ ) and a bottle of massage oil for application to the painful joint twice daily. They were asked to use oral analgesics twice daily till the pain subsides. They were asked to resume it only if pain recurred. They were followed up for 3 weeks and in the end all patients were evaluated by one independent observer (IA). A record was taken of VAS score again and the number of analgesic tablets consumed.

At the conclusion of the data collection the codes were broken and the data was compiled into two groups by the statistician to compare the usage of oral analgesics during the treatment period and VAS score. It was presumed that the two groups would show differences between analgesic consumption and VAS score because of addition of Aloe Vera gel in one group and none in the other.

\section{Results}

Both groups comprised of 20 subjects each and had similar characteristics for age/sex/laterality of joint involved. The epidemiological characteristics of the groups were similar (Table 1). All the subjects completed the treatment regimen of 3 weeks and kept coming for follow up visits. At the end of the study all the data was analyzed by the statistician to see the differences between the usage of analgesics by each group and the (pre-treatment vs post-treatment VAS scores.

Group - A comprised of 14 males and 6 females while Group - B had 6males vs. 4 females. The involvement of right sided knees was $8 \& 6$ in groups $A \& B$ respectively. They had all used the oil with addition of Aloe Vera gel before blinding labeling was done. In All 13 patients in both groups had 13 bilateral involvements. The usage of analgesics per week was low in group B but the difference between the groups was low. The difference in VAS score was apparent but the Group - B patients reported less overall pain than the Group - A at the conclusion of the study. It was observed that patients who had been given massage oil with addition of Aloe Vera gel showed less use of oral analgesics during study period and their VAS scores were less as compared to the Group - A who were using the same massage oil but without Aloe Vera Gel.

9 ANNALS VOL 22, ISSUE 1, JAN. - MAR. 2016 
There were no dropouts or refusal to continue treatment by the subjects. Patients in both groups complained of local irritation and hearth upon application of the oil. No allergic reactions were reported.

\section{Discussion}

Usage of Aloe vera has been proposed by many sources since ancient times to cure joint pains but no scientific study has been done as yet. It had been used orally as well as oil/gel to apply locally to joints. ${ }^{9-11}$ The usage has been popularized by many alternative medical sources through internet and even before that there have not been many publications of isolated usage of the drug to treat arthritis symptoms. Our study has been a very preliminary inquiry to substantiate its effect if any when used in combination with other aromatic oil ingredients for local massage in cases of primary osteoarthritis of the knees. Aloe may alter blood sugar levels if taken orally apart from its effects upon skin and joints. ${ }^{3,7}$ Caution is advised when using herbs or supplements concomitantly that may also alter blood sugar. Blood glucose levels may require monitoring, and doses may need adjustment. Because aloe contains estrogen like chemicals, the effects of other agents believed to have estrogen - like properties may be altered. ${ }^{10}$ Aloe Vera may also interact with anesthetics; antifungals; antiinflammatories and many more because of its reported drug interactions with many groups of medications. ${ }^{11-}$ ${ }^{13}$ Because of low level of evidence available to support such findings very little scientific work is accessible to explain the interactions and effects of Aloe Vera in treatment of joint disorders. It has been used both orally and as local application. The addition of Aloe Vera gel to the commercially available massage oil has been tried in this study in order to see pure effect of local application of Aloe Vera as an additive. Our quest was to see the effect of the drug isolated from confounding variables. Only cases with one disorder were included i.e. osteoarthritis knees. Same commercially available massage oil was selected for use by all patients. The only difference between the two groups was addition of Aloe Vera gel to the same oil. The progressive decline in usage of oral analgesics reflects upon the beneficial effect of the oil upon joint pain. VAS also fell progressively in both groups. The groups only differed marginally in end point evaluations of analgesic usage and VAS. The effect of the oil in the group B seems to have better control of pain than group A. Our presumption is that Aloe Vera in some way can be the factor responsible. It may have anti-inflammatory properties or may be augmenting the same effect in other ingredients in the massage oil. There is another hypothetical possibility that (since it is known to have effects upon skin) the improved efficacy of the massage oil maybe due to increased local absorption of the aromatic oils. Nothing more than this presumption can be offered as our study model is deficient in studying individual ingredient of the oil. No drug interactions are known for these ingredients. We have deliberately avoided such extension of the study due to lack of local facilities and the funding at present. However we do not deny that further work on the subjects looks promising.

\section{Conclusion}

Aloe Vera as local application seems to improve pain relief and decrease oral analgesic use in patients of osteoarthritis knees who are being treated with local massage oils of alternative medical origin. Further studies need to be done to reach a conclusion.

\section{Acknowledgements}

Mr Jasim Matloob statistician and Dr Mohammad Usman Amir were helpful in improving the study model and double blinding.

\section{References}

1. Aloe Vera: http://en.wikipedia.org/wiki/Aloe_vera 
2. Boudreau MD, Beland FA. An Evaluation of the Biological and Toxicological Properties of Aloe Barbadensis (Miller), Aloe Vera. J Environ Sci Health C Environ Carcinog Ecotoxicol Rev. 2006; 24 (1): 103-54.

3. Ernst E. Adverse effects of herbal drugs in dermatology. Br. J. Dermatol. 2000; 143 (5): 923-9.

4. Marshall JM. Aloe vera gel: what is the evidence? Pharm J. 1990; 244: 360-362.

5. King GK, Yates KM, Greenlee PG, Pierce KR, Ford $\mathrm{CR}$, McAnalley $\mathrm{BH}$ et al. The effect of Acemannan Immunostimulant in combination with surgery and radiation therapy on spontaneous canine and feline fibrosarcomas. J Am Anim Hosp Assoc. 1995; 31 (5): 43947.

6. Eshun K, He Q. Aloe vera: a valuable ingredient for the food, pharmaceutical and cosmetic industries - a review. Crit Rev Food Sci Nutr. 2004; 44 (2): 91-6.

7. King GK, Yates KM, Greenlee PG, Pierce KR, Ford $\mathrm{CR}$, McAnalley $\mathrm{BH}$ et al. The effect of Acemannan Immunostimulant in combination with surgery and radiation therapy on spontaneous canine and feline fibrosarcomas. J Am Anim Hosp Assoc. 1995; 31 (5): 43947.

8. Eshun K, He Q. Aloe vera: a valuable ingredient for the food, pharmaceutical and cosmetic industries - a rev- iew. Crit Rev Food Sci Nutr. 2004; 44 (2): 91-6.

9. King GK, Yates KM, Greenlee PG, Pierce KR, Ford $\mathrm{CR}$, McAnalley $\mathrm{BH}$ et al. The effect of Acemannan Immunostimulant in combination with surgery and radiation therapy on spontaneous canine and feline fibrosarcomas. J Am Anim Hosp Assoc. 1995; 31 (5): 43947.

10. Aloevera [Internet]. National Centre for complementary and integrative health: [Updated 2016 Jan 5; cited year Month data]. Available from: http://www.nccih.nih.gov/health/aloevera

11. Aloe (Aloevera) [Internet].Mayo Clinic; [Updated 2013 Nov 1; cited year Month Data]. Available from: http://www.mayoclinic.org/drugsupplements/background/nrb-20058665.

12. Rheumatoid Arthritis. PubMed Health Glossary; [Updated 2012 Apr 01; cited year Month Date]. Available from: http://www.ncbi.nlm.nih.gov/pubmedhealth/PMIAT002 4678/

13. Aloevera [Internet]. Mayo Clinic; [Updated 2013 Apr 1; Cited year Month Date]. Available from: http://www.mayoclinic.org/drugssupplements/aloe/interactions/hrb-200 58665 